\title{
Does Fiscal Policy Matter? Blinder and Solow Revisited
}

\author{
Roger E.A. Farmer and Dmitry Plotnikov* \\ Department of Economics, UCLA \\ 8283 Bunche Hall \\ Box 951477 \\ Los Angeles CA 90095-1477 \\ rfarmer@econ.ucla.edu \\ dplotnikov@ucla.edu
}

First Version: October 2010

This version: April 23, 2011

\begin{abstract}
This paper uses the old-Keynesian representative agent model developed in Farmer (2010b) to answer two questions: 1) do increased government purchases crowd out private consumption? 2) do increased government purchases reduce unemployment? Farmer compared permanent tax financed expenditure paths and showed that the answer to 1) was yes and the answer to 2) was no. We generalize his result to temporary
\end{abstract}

${ }^{*}$ We wish to thank the National Science Foundation for funding this research under grant 0720839. We would also like to thank a referee of this journal for his/her helpful comments. The title of the paper is borrowed from Blinder and Solow (1973) who asked the same question nearly forty years ago in the context of the IS-LM model. 
bond-financed paths of government purchases that are similar to the actual path that occurred during WWII. We find that a temporary increase in government purchases does crowd out private consumption expenditure as in Farmer (2010b). However, in contrast to Farmer's experiment we find that a temporary increase in government purchases can also reduce unemployment.

\section{Introduction}

Economists are still debating the causes of the Great Depression seventy years later. ${ }^{1}$ For thirty years after the publication of The General Theory of Employment Interest and Money (1936) the dominant theory attributed the Depression to a lack of aggregate demand. Most contemporary interpretations of Keynes are based on the idea that unemployment occurs because prices and wages adjust slowly in response to monetary shocks (Clarida, Galí, and Gertler, 1999; Galí, 2008; Woodford, 2003). In a series of books and papers, Farmer (2008a,b, 2009, 2010b,c,d) develops an alternative interpretation of Keynesian economics that does not rely on sticky prices. In (2010b) he raises the possibility, in a representative agent model with Keynesian unemployment, that a permanent increase in government expenditure will be ineffective at restoring full employment.

Farmer's (2010d) paper compared two steady state policies within the context of the old-Keynesian model. In that model, confidence is an independent driving variable that determines the amount that households are willing to pay

\footnotetext{
${ }^{1}$ Monetary explanations of the Great Depression include the work of Friedman and Schwartz (1963) who blame the Fed for failing to prevent a collapse of the money supply and Bernanke (1983) who points to the effects of banking panics. Real explanations include the work of Temin (1978) who cites an autonomous drop in consumption, Ohanian (2009) who blames Herbert Hoover's labor policies and Cole and Ohanian (2004) who argue, using a neo-classical model, that the industrial policy of President Roosevelt's New Deal made an ordinary recession much worse. McGrattan and Ohanian (2011, Forthcoming) have used the same model to study the role of fiscal policy in aiding the recovery. Our paper is most closely related to Harrison and Weder (2006) who use a model with an indeterminate steady state to explain the Great Depression. In contrast, our model is one with a continuum of steady states.
} 
for assets. Farmer studied what would happen if an exogenous drop in confidence were to shift the economy from an equilibrium with full employment to a new equilibrium with high unemployment. By assumption, confidence would remain low for all future periods. He showed, in the context of that model, that a class of stationary balanced budget fiscal policies cannot restore full employment.

In this paper we revisit that result by studying temporary increases in government purchases. Our work is motivated by US experience during WWII when government purchases increased from $16 \%$ of GDP to $52 \%$ and government debt climbed from $40 \%$ of GDP to $120 \%$ in the space of three years.

In the paper we prove two propositions. First, we generalize the crowding out result of Farmer (2010b, Proposition 6.3, page 103) to non-stationary sequences of government expenditures. Second, we study a stylized class of policies in which there is a temporary boost to government expenditure of fixed duration. This class mimics the experience of the US during WWII. We prove, for this class of policies, that unemployment falls temporarily during the period of fiscal expansion. At the end of the boost it falls back to the level that would have occurred in the absence of the expansion.

We show that our model can quantitatively explain the movements in the unemployment rate and consumption during WWII by feeding into the model the actual paths of stock market wealth and government expenditures that occurred during this period. In the conclusion, we discuss the implications of our results for current economic policy.

\section{Keynesian Economics and Crowding Out}

In Farmer and Plotnikov (2010) we show graphical evidence that stock market wealth was highly correlated with unemployment during the 1930s and again 
during the last decade. According to Keynes, the drop in the value of the markets caused the Great Depression. But even if we were to accept this explanation, one would still be left with the puzzle of what generated the remarkable recovery that occurred with the onset of WWII. From 1938 to 1950 the stock market and unemployment were unrelated whilst unemployment fell from $20 \%$ in June 1938 to $1.2 \%$ in February 1944. An obvious candidate to explain the recovery is the huge increase in the size of government that occurred as the economy geared up for and entered WWII.

In textbook Keynesian analysis, fiscal policy works because consumption depends on income. But research on the consumption function after WWII (Dusenberry, 1949; Friedman, 1957) found that consumption is better explained by wealth. Milton Friedman developed the permanent income theory in which he explained how long-lived agents would plan to smooth out their consumption over time. His theory predicts that households will expect an increase in government borrowing to lead to future tax increases.

The permanent income theory predicts that increased government purchases will crowd out private consumption expenditure. Crowding out reduces the stimulative effect of increased government purchases and, in the extreme case, every dollar spent by government may cause households to consume one dollar less. In this extreme case fiscal policy will have no effect on output or employment and Farmer (2010b) showed that this is exactly what happens in the old-Keynesian model if a fiscal expansion is permanent.

This paper asks a simple question in the same model: Can a reduction of unemployment be explained by a temporary increase in government purchases similar to the expansion that occurred in the US during WWII? 


\section{The Old-Keynesian Model}

We assume that utility is logarithmic and that households have access to one period nominal bonds. Since there is no aggregate uncertainty, markets are complete. The assumption that utility is logarithmic implies that the following Euler equation holds in nominal terms,

$$
\frac{1}{C_{t}}=\frac{\beta}{C_{t+1}}\left(1+i_{t}\right)
$$

where $C_{t}$ is the dollar value of consumption expenditure and $i_{t}$ is the nominal interest rate.

Households' assets are the liabilities of a competitive financial sector which holds capital and government bonds. We assume that capital is non-reproducible and that it is valued at the price $p_{k, t}$. Capital is rented to the firms for the rental rent $r r_{t}$. The no arbitrage condition between investing in government bonds and investing in capital implies

$$
1+i_{t}=\frac{p_{k, t+1}+r r_{t+1}}{p_{k, t}}
$$

The price of capital is not equal to the price of the consumption good because capital and consumption are different goods. We assume that there is one unit of non-reproducible capital.

We define $Z_{t}$ to be the money value of GDP. From the national income accounting identity this is equal to the sum of nominal consumption $C_{t}$ and nominal government expenditure $G_{t}$,

$$
Z_{t}=C_{t}+G_{t}
$$

The structure of the labor market is explained in Farmer (2010b). Briefly, we 
assume two technologies; one for producing goods and one for matching workers with jobs. Firms take wages and prices as given and they allocate workers between production and recruiting to maximize profit. Farmer shows that this leads to a reduced form technology

$$
y_{t}=Q_{t}^{1-\alpha} L_{t}^{1-\alpha} K_{t}^{\alpha}
$$

where $Q_{t}$ is an externality that depends on the number of workers being hired in the aggregate economy and $y_{t}$ is the real value of output measured in physical units. $^{2}$

This economy has the same two first order conditions as a standard neoclassical economy. These are represented by equations (5) and (6),

$$
\begin{gathered}
(1-\alpha) Z_{t}=w_{t} L_{t}, \\
\alpha Z_{t}=r r_{t},
\end{gathered}
$$

where $Z_{t}=p_{t} y_{t}$ is nominal GDP as defined above.

\section{Wages and the Labor Market}

The model we have developed looks a lot like a one good representative agent model with a fixed labor supply. It behaves very differently. We assume that every household sends a measure 1 of workers to look for a job every period and that $L_{t}$ of them find a job. To keep the labor market dynamics simple, we assume that the entire work force is fired every period and the process starts again next period.

Since this is a general equilibrium model without money, we are free to

\footnotetext{
${ }^{2}$ This assumption generalizes to an economy with many different consumption goods and multiple capital goods. See Farmer (2010b).
} 
pick the numeraire. As in Farmer (2009) we choose the money wage to be the numeraire by setting

$$
w_{t}=1
$$

To map our model economy into the data we will normalize nominal variables by a measure of the money wage. The money wage grows because of inflation and because of productivity improvements. By deflating GDP, consumption and government purchases by the money wage we are able to generate data series that are stationary.

\section{What the Government Does}

Households each supply one unit of labor and pay a labor income tax $\tau_{t} L_{t}$. Since labor is inelastically supplied, this tax is non distortionary. We abstract from capital taxes and sales taxes. We assume that government purchases $G_{t}$ dollars worth of goods in period $t$ and that the service flow provided by these goods is separable from private consumption in utility. Government chooses sequences $\left\{\tau_{t}, G_{t}, B_{t}\right\}$ that satisfy the intertemporal budget constraint

$$
\sum_{s=t}^{\infty}\left(\frac{1}{1+i_{s}}\right)^{s-t} G_{s}+B_{t}\left(1+i_{t-1}\right)=\sum_{s=t}^{\infty}\left(\frac{1}{1+i_{s}}\right)^{s-t}(1-\alpha) \tau_{s} Z_{s}
$$

Here, $B_{t}$ is nominal government debt, $G_{t}$ is nominal government expenditure and $\tau_{t}$ is the tax rate on labor income.

\section{Closing the Model with Beliefs}

Most models of search are closed by assuming that firms and workers bargain to determine the wage. Following Farmer (2010b), we assume instead that 
workers and firms take the wage and the price as given. This leads to a labor market with one less equation than unknown. To close the model we assume that households form a sequence of self-fulfilling beliefs about the value of assets. We operationalize this assumption by taking the sequence $\left\{p_{k, s}\right\}_{s=t}^{\infty}$ to be chosen exogenously. ${ }^{3}$ We call this sequence the state of expectations.

For any given state of expectations, our model contains the following four equations,

$$
\begin{gathered}
\frac{1}{Z_{t}-G_{t}}=\frac{\beta}{Z_{t+1}-G_{t+1}}\left(1+i_{t}\right), \\
1+i_{t}=\frac{p_{k, t+1}+\alpha Z_{t+1}}{p_{k, t}} \\
L_{t}=(1-\alpha) Z_{t} \\
\sum_{s=t}^{\infty}\left(\frac{1}{1+i_{s}}\right)^{s-t} G_{s}+B_{t}\left(1+i_{t-1}\right)=\sum_{s=t}^{\infty}\left(\frac{1}{1+i_{s}}\right)^{s-t}(1-\alpha) \tau_{s} Z_{s},
\end{gathered}
$$

together with the initial condition,

$$
B_{t}=\bar{B}_{t}
$$

A fiscal policy is a set of sequences $\left\{B_{s+1}, G_{s}, \tau_{s}\right\}_{s=t}^{\infty}$. If there exists a solution to equations (9)-(13) that remains bounded for all $t$ we say that the fiscal policy is feasible. A perfect foresight equilibrium given the state of expectations $\left\{p_{k, s}\right\}_{s=t}^{\infty}$ is a feasible fiscal policy and a bounded set of sequences $\left\{Z_{t}, i_{t}, L_{t}\right\}$ that satisfy equations (9)-(13).

\footnotetext{
${ }^{3}$ Farmer (2010a) shows how to operationalize the idea of animal spirits by defining a belief function. He estimates a three equation old-Keynesian model and shows that it fits the US data better than a three equation new-Keynesian model.
} 


\section{$7 \quad$ Steady State Solution}

Farmer (2010b) showed that a stationary equilibrium of the model for a given state of expectations $\left\{p_{k, s}\right\}_{s=t}^{\infty}$ and a stationary sequence of government expenditures $G_{s}=G$ for $s=t \cdots \infty$ implies

$$
C_{s}+G_{s}=Z_{s}=\frac{1-\beta}{\beta \alpha} p_{k}, \text { for all } s .
$$

Two interesting facts follow from Equation (14). First, one additional dollar of government expenditure decreases private consumption by one dollar. This follows because the RHS of Equation (14) does not depend on government expenditure, $G_{s}$. Second, the stationary equilibrium value of GDP depends on the state of expectations, $p_{k}$. Farmer (2010b) shows that $p_{k}$ can taken any value in a bounded set and it follows from this fact that there is a continuum of stationary equilibria, each supported by a different stationary value of $p_{k}$ and each associated with a different stationary unemployment rate.

Now consider the following experiment. Let the state of expectations fall from $p_{k, 1}$ to $p_{k, 2}$ where

$$
p_{k, 2}<p_{k, 1}
$$

In the new stationary equilibrium, GDP will be lower and the unemployment rate will be higher. If expectations about the future prices of the assets in the economy never recover, the economy will be in a new equilibrium with a higher unemployment rate for ever. But how does the economy behave if $p_{k, t}$ and $G_{t}$ are not constant sequences? Will the above result about crowding out hold? We turn to that question next. 


\section{Main Results}

This section presents the main results of the paper. First, we show that increased government spending lowers consumption. Second, we show that a temporary increase in government purchases can increase employment in the short-run.

The following proposition compares two economies: one with and one without government intervention. We hold the state of expectations fixed. The proposition states that there is a crowding out effect: private consumption will be lower in the economy with government spending. ${ }^{4}$

Proposition 1 Consider two economies with the same state of expectations $\left\{p_{k, s}\right\}_{s=t}^{\infty}$ but with different feasible non-negative expenditure sequences $\left\{G_{s}\right\}_{s=0}^{\infty}$ and $\left\{\tilde{G}_{s}\right\}_{s=0}^{\infty}$. Let $\left\{\tilde{G}_{s}\right\}_{s=0}^{\infty}$ be equal to zero for all s. Let there be a date $T$ such that $G_{s}=0$ for all $s>T$ and $G_{s}>0$ for all $s \leq T$. Then there is crowding out in the following sense. If $\left\{C_{s}\right\}_{s=t}^{\infty}$ is the sequence of private consumption in the first economy and if $\left\{\tilde{C}_{s}\right\}_{s=t}^{\infty}$ is the sequence of private consumption in the second economy then $\tilde{C}_{s}>C_{s}$ for all $s<T$.

Proof. See Appendix A.

A statement about the exact effect of a government expansion on unemployment is more difficult to prove. Ideally one would want to have a condition for each sequence of government expenditures that would tell us, depending on parameter values and the state of expectations, whether such a policy will decrease or increase employment in the current and the following periods. We have not been able to prove a statement with this degree of generality.

Instead, we focus on a specific class of non-stationary fiscal policies, inspired by the experience of actual fiscal policy before and after WWII. Government purchases were approximately $16 \%$ of GDP before WWII. During the war they

\footnotetext{
${ }^{4}$ It is easy to extend this result to the case where expenditure is positive in the second economy but lower than in the first economy in every period. The extension of the proof is straightforward and is omitted.
} 
peaked at $52 \%$ and at the end of WWII they increased permanently to a new higher level of $23 \%$ of GDP.

We characterize this policy by studying the class of fiscal expansions depicted in Figure 1. We compare two economies with the same state of expectations but different fiscal policies. In the control economy there is a predetermined sequence of government expenditures $\tilde{G}_{s}$. In the treatment economy government expenditure increases by a fixed factor, $\Delta>1$ at time $s=t_{1}{ }^{5}$ and remains at $\Delta \cdot \tilde{G}_{t}$ for $t_{2}-t_{1}$ periods. After period $t_{2}$, expenditure reverts to the sequence $\tilde{G}_{s}$. Figure 1 depicts a special case of this class where $\left\{\tilde{G}_{t}\right\}$ is constant for $s<t_{2}$ and increases to a new higher level after date $t_{2}$.

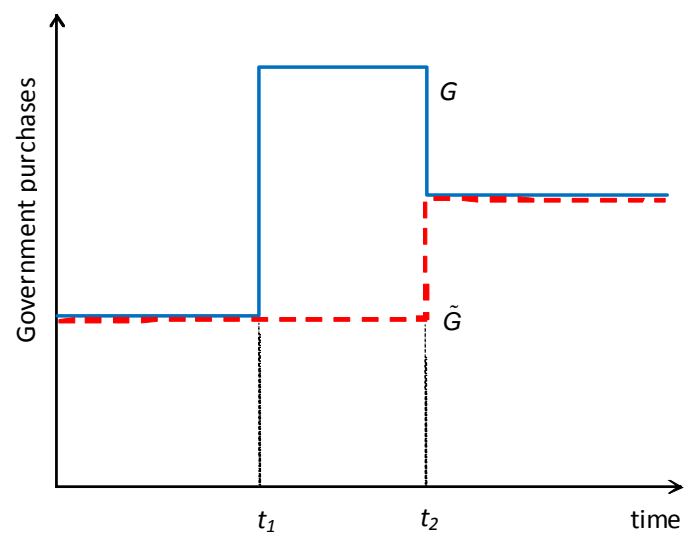

Figure 1: Government Purchases in the Treatment and Control Economies

Given these policies we prove that the change in fiscal policy reduces unemployment during the expansion period at the cost of higher unemployment before the expansion. If the policy is unanticipated, it reduces unemployment during the expansion period with no cost. This corresponds to the case $t_{1}=0$.

Proposition 2 Consider two economies with the same state of expectations $\left\{p_{k, s}\right\}_{s=t}^{\infty}$ but with different feasible non-negative expenditure sequences $\left\{G_{s}\right\}_{s=0}^{\infty}$ and $\left\{\tilde{G}_{s}\right\}_{s=0}^{\infty}$ in "treatment" and "control" economies. Let these sequences satisfy the properties,

\footnotetext{
${ }^{5}$ This experiment makes sense if $\tilde{G}_{s}>0$ which we assume from now on.
} 


$$
G_{s}= \begin{cases}\tilde{G}_{s} & \text { if } s<t_{1}, \\ \Delta \times \tilde{G}_{s} & \text { if } t_{1} \leq s \leq t_{2}, \text { where } \Delta>1 \text { is a constant } \\ \tilde{G}_{s} & \text { if } t_{2}<s .\end{cases}
$$

These assumptions imply that the treatment economy undergoes a fiscal expansion during the time interval $\left\{t_{1} \ldots t_{2}\right\}$. Let $\left\{U_{s} \equiv 1-L_{s}\right\}$ and $\left\{\tilde{U}_{s} \equiv 1-\tilde{L}_{s}\right\}$ be the unemployment rates in each economy. There exists an integer $T \geq 1$, where $t_{2} \equiv t_{1}+T$, such that,

Part $1 U_{s}=\tilde{U}_{s}$ for $s>t_{2}$,

Part $2 U_{s}>\tilde{U}_{s}$ for $s<t_{1}$,

Part $3 U_{s}<\tilde{U}_{s}$ for $t_{1} \leq s \leq t_{2}$.

Proof. See Appendix B.

Part 3 of Proposition 2 implies that a temporary fiscal policy expansion will reduce unemployment and it provides a basis for understanding why the boost in government purchases that occurred in 1941-1945 resulted in the end of the Depression. This proposition implies that a boost to fiscal spending will be effective at increasing employment for a finite time.

Our next proposition discusses the effect of changing the length of the expansion period on the effectiveness of fiscal policy. One might think that government would want to increase the length of the fiscal expansion in order to exploit the benefit of an increase in government expenditure on the unemployment rate. Proposition 3 implies that a permanent increase in government expenditure at time $s=t_{1}$ will have no effect on the unemployment rate. Moreover, the positive effect on the unemployment rate at the beginning of the expansion becomes smaller at an exponential rate as the anticipated length of the expansion increases. 
Because we are interested in the asymptotic behavior of GDP, we need to specify what happens to government expenditure in the limit. We will focus our analysis on the case when the share of government expenditure to GDP is constant as $t_{2} \rightarrow \infty$. We distinguish two cases. As $t_{2} \rightarrow \infty$ :

$$
\begin{aligned}
& \lim _{s \rightarrow \infty} \beta\left(1+\alpha \frac{G_{s}}{p_{k, s}}\right) \equiv \beta(1+\alpha x)<1, \\
& \lim _{s \rightarrow \infty} \beta\left(1+\alpha \Delta \frac{G_{s}}{p_{k, s}}\right) \equiv \beta(1+\alpha \Delta x) \geq 1,
\end{aligned}
$$

Or

$$
\begin{aligned}
& \lim _{s \rightarrow \infty} \beta\left(1+\alpha \frac{G_{s}}{p_{k, s}}\right) \equiv \beta(1+\alpha x)<1, \\
& \lim _{s \rightarrow \infty} \beta\left(1+\alpha \Delta \frac{G_{s}}{p_{k, s}}\right) \equiv \beta(1+\alpha \Delta x)<1 .
\end{aligned}
$$

The first inequality that is common to Condition A and Condition B is necessary for the expenditure plan $\left\{\tilde{G}_{s}\right\}$ to be feasible given that households hold expectations $\left\{p_{k, s}\right\}$. The second inequality of Condition A will be satisfied if the increase in government purchases, represented by $\Delta$, is large enough. In this case Proposition 3 implies that a boost to fiscal spending will only be effective at increasing employment for a limited time.

The second inequality of Condition B implies that the fiscal expansion is relatively small. Proposition 3 states that in this case an expansion in government spending, that is known to end at a some future date, will lower unemployment for an arbitrarily long period of time. But the longer the policy is expected to last, the less effective it will be when it is first implemented. Moreover, effectiveness at date $t_{1}$, decreases exponentially as $t_{2} \rightarrow \infty$.

Proposition 3 Consider two economies with the same state of expectations $\left\{p_{k, s}\right\}_{s=t}^{\infty}$ but with different feasible non-negative expenditure sequences $\left\{G_{s}\right\}_{s=0}^{\infty}$ and $\left\{\tilde{G}_{s}\right\}_{s=0}^{\infty}$ in "treatment" and "control" economies. Let these sequences satisfy the properties, 


$$
G_{s}= \begin{cases}\tilde{G}_{s} & \text { if } s>t_{2} \\ \Delta \times \tilde{G}_{s} & \text { if } t_{1} \leq s \leq t_{2}, \quad \Delta>1 \\ \tilde{G}_{s} & \text { if } s<t_{1}\end{cases}
$$

Let $\left\{U_{s}\right\}$ and $\left\{\tilde{U}_{s}\right\}$ be the unemployment rates in each economy and let $\Delta>1$ and $x>0$ be constants. Then

1. $U_{s}=\tilde{U}_{s}$ for $s>t_{2}$

2. $U_{s}>\tilde{U}_{s}$ for $s<t_{1}$

(a) If Condition $A$ holds then there exists an integer $T \geq 1$ such that

i. If $\left|t_{2}-t_{1}\right| \leq T$ then $U_{s}<\tilde{U}_{s}$ for $t_{1} \leq s \leq t_{2}$

ii. If $\left|t_{2}-t_{1}\right|>T$ then $U_{s}>\tilde{U}_{s}$ for $t_{1} \leq s<t_{2}-T$ and $U_{s}<\tilde{U}_{s}$ for $t_{2}-T \leq s \leq t_{2}$

(b) If Condition $B$ holds then $U_{s}<\tilde{U}_{s}$ for $t_{1} \leq s \leq t_{2}$, but for all fixed $\bar{s} \in\left[t_{1}, t_{2}\right) U_{\bar{s}} \rightarrow \tilde{U}_{\bar{s}}$ as $t_{2} \rightarrow \infty$ monotonically at an exponential rate.

Proof. See Appendix C.

Note that as a special case, Proposition 3 states that if Condition B holds and if $t_{2}=\infty$, then $U_{s}=\tilde{U}_{s}$ for all $s \geq t_{1}$. In other words, the fiscal expansion has no effect on the unemployment rate.

\section{An Application to the Data}

Our theory predicts that movements in the unemployment rate are caused by movements in aggregate demand. To address the plausibility of our explanation, we took the observed movements in wealth and government purchases from the data and we used them to infer the implied movements in consumption from our model. 
We used government purchases from the NIPA accounts and the S\&P 500 and we deflated both series by a measure of the nominal wage. The wage series was also constructed from NIPA data using the methodology described in Farmer (2010b). Using these series we fixed $C_{T}$ where $T=1947$ and we calculated the implied consumption series by setting $\alpha=0.33, \beta=0.96$ and using the actual values of the series on government expenditure and the stock market $\left\{G_{s}, p_{k, s}\right\}_{s=1929}^{1947}$, by solving Equations (9)-(13). The result of this experiment is graphed in Figure 2.

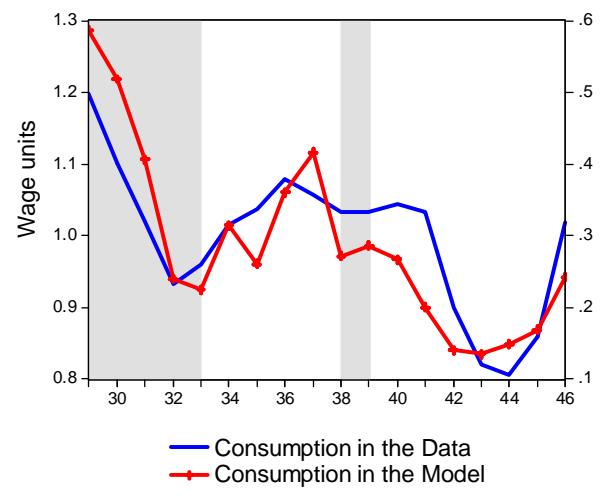

Figure 2: Consumption in the Data and in the Model

Since the $\mathrm{S} \& \mathrm{P}$ is an index number, the units of our real wealth variable are only defined up to a scalar multiple where the weight attached to each data point reflects money prices at the inception date of the index. We normalized the value of the index by scaling the $\mathrm{S} \& \mathrm{P}$ series by 579 , a value that implies that the economy was in a steady state in 1929 . This scaling factor, $\mu$, is defined by the steady state relationship

$$
\mu=\frac{C_{1929}+G_{1929}}{p_{k, 1929}} \frac{\beta \alpha}{(1-\beta)}
$$




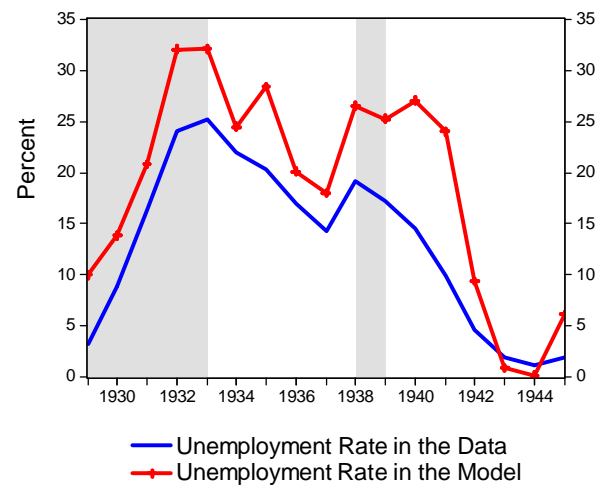

Figure 3: Unemployment in the Data and in the Model

The model predicts that consumption is related to wealth. Since the S\&P is only a partial measure of all tangible assets, our model is unlikely to capture all of the movements in employment and consumption in the data. We would hope, however, the model is capable of capturing the movements in the consumption series implied by changes in government expenditure and in stock market wealth. The fact the actual and model series for consumption move relatively closely gives us some encouragement that the theory is on the right track.

In Figure 3 we plot the unemployment rate in the data and the unemployment rate implied by our model using Equation (11) where $Z_{t}$ is the sum of the actual government expenditure series and the consumption series implied by our model.

We have more confidence in the movements of this series than in its level which is sensitive to a normalization constant that defines the supply of labor. Notice that our model is able to capture the reduction in the unemployment rate as the US economy gears up for WWII which occurs as a result of the huge increase in government purchases that began in 1941.

Since our model assumes that capital is fixed, we are unable to discuss the effects of government purchases on investment. Barro 2008 has argued 
that these effects were substantial and that consumption moved very little in response to a fiscal expansion during WWII. Our own analysis (see Farmer and Plotnikov (2010)) finds a measurable impact of government purchases on consumption when series are measured in wage units. Part of the discrepancy with Barro's findings are caused by this difference in the deflator. We chose the model with fixed capital because it allows us to discuss, in a relatively simple model, what happens to unemployment in response to a change in the relative price of capital. In the one-good real business cycle model this relative price is always one and that is not a good framework for thinking about stock market movements. ${ }^{6}$

We can also use our model to ask a second question. What would have happened to the unemployment rate in the early 1940s if the government had not increased expenditures from $16 \%$ to $52 \%$ of the economy and if the stock market had followed the same path that we observed during this period? To answer this question we took the same series for $p_{k, t}$, but we fed in a different series for government expenditures for the years 1941 - 1945 by assuming that government spending during these years remained at the 1940 level. Since we are treating the state of expectations as an independent variable, that is a legitimate question within the context of the model. Figure 4 presents results of this experiment. The actual unemployment rate is plotted on the left axis and the model unemployment rate on the right.

\footnotetext{
${ }^{6}$ We are currently working on an extension of these results to models that allow for investment by incorporating a cost of adjustment and more realistic labor market dynamics.
} 


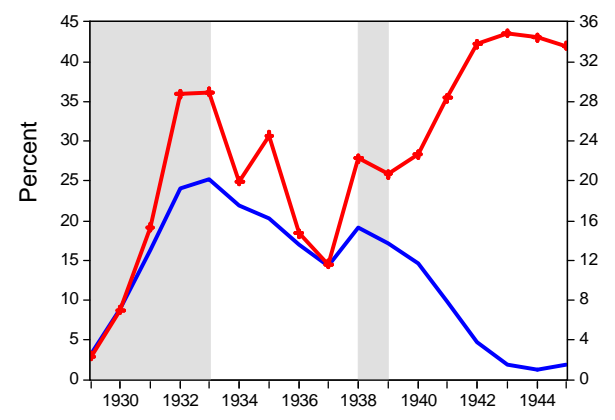

- Unemployment Rate in the Data

$\rightarrow$ Estimated Unemployment Rate in the Absence of a Stimulus

Figure 4 Predicted Unemployment without a Fiscal Stimulus

The model predicts that without a large fiscal stimulus, and conditional on the actual path of the stock market, the unemployment rate would have increased dramatically in the early 1940s. These findings are consistent with propositions 1 and 2 which show that a temporary increase in government expenditure is predicted to crowd out consumption and reduce unemployment.

\section{Conclusion}

To summarize, the paper studies the effect of an expansionary fiscal policy on output and employment in the economy using Farmer's (2010b) old-Keynesian framework. We find that expansionary fiscal policy increases economic activity and reduces unemployment in the short-run at the cost of reduced consumption. If the stimulus is foreseen, there will be an additional cost of reduced employment in the years leading up to the increase in government purchases.

Given its simplicity, the model does a good job of fitting actual data for the period of the Great Depression and the early years of WWII. It is encouraging that the dynamic version of the model can explain why a fiscal stimulus increased employment in the 1940s since the steady state version of the same model implies $100 \%$ crowding out of consumption and no effect on the unemployment rate. 
But the fact that a temporary fiscal stimulus can be shown to increase employment does not mean that it is the right policy to cure a depression. The crowding out of consumption that occurs in the model implies a substantial welfare loss associated with increased government expenditure unless the government purchases goods that have a significant social value. That clearly was the case in WWII since the US was fighting for its survival. Most of the newly employed people were directed to the war effort either directly by enlisting in the army or indirectly by producing munitions.

The case for fiscal stimulus in the current crisis is less clear. If the economy is not self-correcting as Keynes believed, a large fiscal expenditure may not be the best way to restore full employment. In the model we have outlined in this paper, it is critical to increase the value of confidence in the value of private wealth in order to permanently restore jobs.

\section{Appendix A: Proof of Proposition 1}

To prove Proposition 1 we first prove:

Lemma 1: If there exists a date $s$ for which $\tilde{C}_{s}>C_{s+1}$ then $\tilde{C}_{s}>C_{s}$.

Proof. Combining equations (1), (2) and (6), it follows that $\left\{\tilde{C}_{s}\right\}_{s=t}^{\infty}$ satisfies the equation

$$
\frac{1}{\beta} \frac{p_{k, s}}{\tilde{C}_{s}}=\alpha+\frac{p_{k, s+1}}{\tilde{C}_{s+1}}
$$

and $\left\{C_{s}\right\}_{s=t}^{\infty}$ satisfies

$$
\frac{1}{\beta} \frac{p_{k, s}}{C_{s}}=\alpha+\frac{p_{k, s+1}}{C_{s+1}}+\alpha \frac{G_{s+1}}{C_{s+1}} .
$$


Dividing (A2) by (A1) and defining

$$
f(x)=\frac{1}{\beta} \frac{p_{k, t}}{x}-\alpha,
$$

we have

$$
\frac{f\left(C_{s}\right)}{f\left(\tilde{C}_{s}\right)}=\frac{\tilde{C}_{s+1}}{C_{s+1}}\left[1+\alpha \frac{G_{s+1}}{p_{k, s+1}}\right] .
$$

Since $f(x)$ is decreasing in $x$, it follows that if

$$
\frac{\tilde{C}_{s+1}}{C_{s+1}}\left[1+\alpha \frac{G_{s+1}}{p_{k, s+1}}\right]>1,
$$

then $\tilde{C}_{s}>C_{s+1}$. QED

Proof of Proposition 1. Note that $\tilde{C}_{T+1}=C_{T+1}$ and $\left\{G_{s}=0\right\}_{s=T+1}^{\infty}$ since the economies are identical from date $T+1$ onwards, it follows from (A1) and (A2) that $\tilde{C}_{T}=C_{T}$. Since $G_{s} / p_{k, s}>0$ for $s \leq T$,

$$
\frac{\tilde{C_{T}}}{C_{T}}\left[1+\alpha \frac{G_{T}}{p_{k, T}}\right]>1
$$

But then, it follows from Lemma 1 that $\tilde{C}_{s}>C_{s}$ for $s<T$. QED

\section{Appendix B: Proof of Proposition 2}

Proof. It follows from Equation (11) and the definitions of $U_{t}$ and $\tilde{U}_{t}$ that

$$
U_{s}<\tilde{U}_{s} \Longleftrightarrow Z_{s}>\tilde{Z}_{s} .
$$

Thus, instead of proving a statement about a relationship between unemployment rates, we can prove an equivalent statement about GDP.

Combining (1) and (3) gives the following expressions that must hold in each economy 


$$
\begin{gathered}
\frac{1}{\beta} \frac{p_{k, s}}{C_{s}}=\frac{p_{k, s+1}}{C_{s+1}}+\alpha \frac{G_{s+1}+C_{s+1}}{C_{s+1}}, \\
\frac{1}{\beta} \frac{p_{k, s}}{\tilde{C}_{s}}=\frac{p_{k, s+1}}{\tilde{C}_{s+1}}+\alpha \frac{\tilde{G}_{s+1}+\tilde{C}_{s+1}}{\tilde{C}_{s+1}} .
\end{gathered}
$$

Proof of Part 1: By assumption, the sequence of government expenditures is the same in both economies for $s>t_{2}$. It follows that

$$
C_{s}=\tilde{C}_{s} \quad \forall s>t_{2}
$$

Combining Equation (B4) with the national accounting identity for $s>t_{2}$ we obtain that $Z_{s}=\tilde{Z}_{s} \quad \forall s>t_{2}$. This proves Part 1 .

\section{Proof of Part 2}

Note that, by assumption, there is a fiscal expansion in the treatment economy during the period $\left[t_{1}, t_{2}\right]$. It follows from Proposition 1 , that

$$
C_{s}<\tilde{C}_{s} \quad \forall s<t_{2}
$$

But $G_{s}=\tilde{G}_{s}$ if $s<t_{1}$. It follows from the national income accounting identity that $Z_{s}<\tilde{Z}_{s}, \quad \forall s<t_{1}$. This proves Part 2 .

\section{Proof of Part 3.}

We must show that if $\left|t_{2}-t_{1}\right| \leq T$ where $T$ is a fixed number then

$$
C_{s}+G_{s}>\tilde{C}_{s}+\tilde{G}_{s} \quad \forall t_{1} \leq s \leq t_{2}
$$

Suppose first that $T=\left|t_{2}-t_{1}\right|=1$. Since $C_{T}=\tilde{C}_{T}$, and $G_{T}>\tilde{G}_{T}$, it follows immediately that $Z_{T}>\tilde{Z}_{T}$ and hence a one period increase in government expenditure increases GDP. To establish that $T$ may be greater than 1 , consider the following change of variables. Divide both sides of Equation (B6) 
by $\tilde{G}_{s}$ and define $\tilde{y}_{s}$ and $y_{s}$,

$$
\tilde{y}_{s} \equiv \frac{\tilde{G}_{s}}{\tilde{C}_{s}}, y_{s} \equiv \frac{G_{s}}{C_{s}}
$$

Since we assume that, for $t_{1} \leq s \leq t_{2}$,

$$
\frac{G_{s}}{\tilde{G}_{s}} \equiv \Delta>1
$$

some simple algebra establishes that inequality (B6) is equivalent to the statement

$$
\Delta>\frac{\frac{1}{\tilde{y}_{s}}+1}{\frac{1}{y_{s}}+1} \equiv \frac{1+\tilde{y}_{s}}{g(s)+\tilde{y}_{s}} \equiv f(s),
$$

for all $t_{1} \leq s \leq t_{2}$ where $g(s) \equiv \frac{\tilde{y}_{s}}{y_{s}}$. To establish (B9), we will show (1) that $\tilde{y}_{s}$ and $y_{s}$ each satisfy a non-autonomous quasi-linear difference equation (2) that $\tilde{y}_{s}=y_{s}$ for $s>t_{2}(3) g\left(t_{2}+1\right)=1$ and $(4) g(s)<g(s+1)$ for $t_{1}<s<t_{2}$. Together, these statements imply that $f\left(t_{2}+1\right)=1<\Delta$ and that $f(s)$ is increasing as we move backwards in time from $t_{2}$. Since (B9) is equivalent to (B6), for all $s$ for which $f(s)<\Delta$, a fiscal expansion increases GDP and reduces unemployment. We now turn to the properties of $f(s)$ by showing that (1)-(4) hold.

(1) Define two exogenous variables $\tilde{x}_{s}$ and $x_{s}$

$$
\tilde{x}_{s} \equiv \frac{\tilde{G}_{s}}{p_{k, s}}, x_{s} \equiv \frac{G_{s}}{p_{k, s}}
$$

and let

$$
\lambda_{s} \equiv \beta\left(\frac{x_{s}}{x_{s+1}}+\alpha x_{s}\right), \theta_{s} \equiv \alpha \beta x_{s}
$$

and

$$
\tilde{\lambda}_{s} \equiv \beta\left(\frac{\tilde{x}_{s}}{\tilde{x}_{s+1}}+\alpha \tilde{x}_{s}\right), \tilde{\theta}_{s} \equiv \alpha \beta \tilde{x}_{s}
$$


Using these definitions, it follows from equations (B2) and (B3) that $\left\{y_{s}\right\}$ and $\left\{\tilde{y}_{s}\right\}$ are characterized by the following simple recursions:

$$
y_{s}=\lambda_{s} y_{s+1}+\theta_{s},
$$

and

$$
\tilde{y}_{s}=\tilde{\lambda}_{s} \tilde{y}_{s+1}+\tilde{\theta}_{s}
$$

This establishes (1).

(2) Notice that from date $t_{2}+1$ onwards both economies are identical and hence

$$
\tilde{y}_{t_{2}+1}=y_{t_{2}+1} \text {. }
$$

This establishes (2).

(3) Since $\tilde{y}_{t_{2}+1}=y_{t_{2}+1}$ it follows from the definition of $g(s)$ that $g\left(t_{2}+1\right)=$ 1. This establishes (3).

(4) Notice that for $t_{1} \leq s \leq t_{2}$

$$
\theta_{s}=\Delta \tilde{\theta}_{s}>\tilde{\theta}_{s}, \text { and } \tilde{\lambda}_{s}>\lambda_{s}
$$

For $s=t_{2}$

$$
\lambda_{s}=\Delta \tilde{\lambda_{s}}>\tilde{\lambda_{s}},
$$

while for $t_{1} \leq s<t_{2}$,

$$
\lambda_{t_{2}}=\beta\left(1+\alpha \Delta x_{t_{2}}\right)>\beta\left(1+\alpha x_{t_{2}}\right)=\tilde{\lambda}_{t_{2}} .
$$

Moving backwards in time from $t_{2}$, it follows from (B13)-(B18) that for $t_{1} \leq$ $s \leq t_{2}$,

$$
\frac{y_{s}}{y_{s+1}}>\frac{\tilde{y}_{s}}{\tilde{y}_{s+1}}
$$


and hence

$$
g(s)=\frac{\tilde{y}_{s}}{y_{s}}<\frac{\tilde{y}_{s+1}}{y_{s+1}}=g(s+1) .
$$

This establishes (4).

We have established that $f\left(t_{2}\right)=1<\Delta$ and that $f(s)$ is increasing as $s$ moves back in time from $t_{2}$. It follows that there exists a $T \geq 1$ such that $f(s) \mid s \in\left\{t_{2}-T, \ldots t_{2}\right\}<\Delta$. QED.

\section{Appendix C: Proof of Proposition 3}

Proof. Using the notation from the proof of Proposition 2, there are two possible cases: either at some $s=t_{2}-T, \quad f(s)>\Delta$ or $f(s) \rightarrow \Delta$ as $s \rightarrow$

$-\infty$. The first case correspond to Condition A and the second corresponds to Condition B. It follows from Condition A that for sufficiently small $s$,

$$
\lambda_{s} \equiv \beta\left(\frac{\tilde{x}_{s}}{\tilde{x}_{s+1}}+\alpha \Delta \tilde{x}_{s}\right) \geq 1,
$$

and

$$
\tilde{\lambda}_{s} \equiv \beta\left(\frac{\tilde{x}_{s}}{\tilde{x}_{s+1}}+\alpha \tilde{x}_{s}\right)<1 .
$$

These inequalities imply that the gap between $\tilde{y}_{s}$ and $y_{s}$ will grow as $s$ decreases from $t_{2}$ and hence there must be a $T$ such that at $s=t_{2}-T$, $f(s)>\Delta$. At this point the fiscal expansion will lower output and increase unemployment. This establishes that $T$ is finite if Condition A holds.

Now suppose that Condition B holds. Recall (B9), which we restate below

$$
\Delta>\frac{\frac{1}{\tilde{y_{s}}}+1}{\frac{1}{y_{s}}+1} \equiv \frac{1+\tilde{y}_{s}}{g(s)+\tilde{y}_{s}} \equiv f(s) .
$$


We established in the proof of Proposition 2 that $y_{s}$ and $\tilde{y}_{s}$ satisfy the recursions

$$
y_{s}=\lambda_{s} y_{s+1}+\theta_{s}
$$

and

$$
\tilde{y}_{s}=\tilde{\lambda}_{s} \tilde{y}_{s+1}+\tilde{\theta}_{s}
$$

and since we restrict ourselves to the case where $x_{s} \rightarrow x$ as $s \rightarrow-\infty,{ }^{7}$ it follows from Condition B that $\lambda_{s}, \tilde{\lambda}_{s}, \theta_{s}$ and $\tilde{\theta}_{s}$ are constants in the limit and that $\lambda_{s}$ and $\tilde{\lambda}_{s}$ are both positive and less than one. Hence as $s \rightarrow-\infty$

$$
y_{s} \rightarrow y=\frac{\theta}{1-\lambda}
$$

and

$$
\tilde{y}_{s}=\tilde{y}=\frac{\tilde{\theta}}{1-\tilde{\lambda}} .
$$

From the definitions of $\lambda_{s}, \tilde{\lambda}_{s}, \theta_{s}$ and $\tilde{\theta}_{s}$ and the definition of $f(s)$ one can establish that as $s \rightarrow-\infty$

$$
f(s) \rightarrow \frac{\frac{1-\beta}{\alpha \beta \tilde{x}}}{\frac{1-\beta}{\alpha \beta \Delta \cdot \tilde{x}}}=\Delta .
$$

Since establishing that $f(s)=\Delta$ is equivalent to showing that (B6) holds as an equality we have shown that a fiscal expansion that is expected to persist for an arbitrarily long period will have an arbitrarily small effect on GDP and employment. QED

\footnotetext{
${ }^{7}$ This is identical to the statement that government purchases constitute a constant share of GDP since in the long-run GDP itself is proportional to $p_{k, s}$.
} 


\section{References}

Barro, R. J. (2008): Macroeconomics; a Modern Approach. Thomson, SouthWestern College Publishing, New York.

Bernanke, B. S. (1983): "Nonmonetary Effects of the Financial Crisis in Propagation of the Great Depression," American Economic Review, 73(3), $257-276$.

Blinder, A., And R. M. Solow (1973): "Does Fiscal Policy Matter?," Journal of Public Economics, pp. 319-337.

Clarida, R., J. Galí, and M. Gertler (1999): "The Science of Monetary Policy: A New Keynesian Perspective," Journal of Economic Literature, 37(December), 1661-1707.

Cole, H. L., and L. E. Ohanian (2004): "New Deal Policies and the Persistence of the Great Depression: A General Equilibrium Analysis," Journal of Political Economy, 112(4), 779-816.

Dusenberry, J. S. (1949): Income, Saving, and the Theory of Consumer Behavior. Harvard University Press, Cambridge Mass.

FArmer, R. E. A. (2008a): "Aggregate Demand and Supply," International Journal of Economic Theory, 4(1), 77-94.

— (2008b): "Old Keynesian Economics," in Macroeconomics in the Small and the Large, ed. by R. E. A. Farmer, chap. 2. Edward Elgar, Cheltenham, UK.

— (2009): "Confidence, Crashes and Animal Spirits," NBER WP no. 14846 . 
— (2010a): "Animal Spirits, Persistent Unemployment and the Belief Function," NBER Working Paper 16522.

_ (2010b): Expectations, Employment and Prices. Oxford University Press, New York.

(2010c): How the Economy Works: Confidence, Crashes and Selffulfilling Prophecies. Oxford University Press, New York.

— (2010d): "How to Reduce Unemployment: A New Policy Proposal,”" Journal of Monetary Economics: Carnegie Rochester Conference Issue, 57(5), $557-572$.

Farmer, R. E. A., and D. Plotnikov (2010): "Does Fiscal Policy Matter? Blinder and Solow Revisited," NBER Working Paper number 16644.

Friedman, M. (1957): A Theory of the Consumption Function. Princeton University Press.

Friedman, M., and A. J. Schwartz (1963): A Monetary History of the United States, 186\%-1960. Princeton University Press, Princeton.

Galí, J. (2008): Monetary Policy, Inflation and the Business Cycle. Princeton University Press, New Jersey.

Harrison, S., And M. Weder (2006): "Did Sunspot Forces Cause the Great Depression?," Journal of Monetary Economics, 53, 1527-1539.

Keynes, J. M. (1936): The General Theory of Employment, Interest and Money. MacMillan and Co.

McGrattan, E., and L. Ohanian (2011, Forthcoming): "Does Neoclassical Theory Account for the Effects of Big Fiscal Shocks," International Economic Review. 
Ohanian, L. (2009): "What, - or who, started the Great Depression?," Journal of Economic Theory, 144, 2310-2335.

Temin, P. (1978): "Did Monetary Forces Cause the Great Depression," Journal of Monetary Economics, 4(1), 143-147.

Woodford, M. (2003): Interest and Prices: Foundations of a Theory of Monetary Policy. Princeton University Press, Princeton, N.J. 